\title{
EXTENSOR DIGITORUM BREVIS FLAP ON THE TREATMENT OF LOWER LIMB INJURIES
}

\author{
Luciano Ruiz Torres ${ }^{1}$, Priscilla Messias Paganelli ${ }^{1}$, Renan Pires Negrão dos Santos $^{1}$, Walter Hamilton de Castro Targa $^{1}$, \\ Tulio Diniz Fernandes ${ }^{1}$, Rames MatTar Júnior ${ }^{1}$
}

\section{ABSTRACT}

Objective: To describe our pioneer national experience with 11 patients with soft tissue defects in the distal $1 / 3$ of the leg, ankle and forefoot treated with extensor digitorum brevis muscle flap (EDB). Methods: Between November 2009 and July 201211 patients were operated with the flap technique. We operated nine men and two women aged between 10 and 66 years. The surgical indications were acute trauma in four patients and post-traumatic osteomyelitis in seven patients. The small defects were covered ranging from $3 \times 3$ to $6 \times 3 \mathrm{~cm}$.
The patch was applied with proximal stalk in most cases. Results: Complete healing and infectious cure were obtained in all cases, despite one loss. Conclusion: The EDB flap is a feasible and safe technique to repair foot, ankle and distal leg losses. Suffering, dehiscence and delayed healing of the EDB end flap donor area may, however, occur. L-shaped incisions should be avoided for muscle lifting. Level of Evidence IV, Case series.

Keywords: Wounds and injuries. Surgical flaps. Osteomyelitis.

Citation: Torres LR, Paganelli PM, Santos RPN, Targa WHC, Fernandes TD, Mattar Junior R. Extensor digitorum brevis flap on the treatment of lower limb injuries. Acta Ortop Bras. [online] 2014;22(2):86-9. Available from URL: http://www.scielo.br/aob.

\section{INTRODUCTION}

Wounds in the foot and ankle determine the most complex area of coverage for reconstruction of lower limbs. The presence of terminal vascularization, thin skin, bony prominences and small muscle mass are some of the reasons for this fact.

The traditional microsurgical reconstruction algorithm is proposed for most raw areas of the region. The advent of the study of perforator flaps, ${ }^{1,2}$ however, brought to the reconstructive surgeon's arsenal new local flaps as the flap propeller. ${ }^{3}$ Taken together, the medical literature has been making contributions on the rapprochement with old patchwork with technical modifications, ${ }^{4}$ allowing transposition of the largest tissue islands, longer range and less potential damage to the donor site. In this topic, Georgescu ${ }^{5}$ added a new concept to the definition of Microsurgery, the microsurgical dissection without actual microvascular anastomosis.

The extensor digitorum brevis muscle (EDB) has been used as interposition tissue in surgical technique for the treatment of tarsal coalition since $1927 .{ }^{6,7}$ In these cases it was used more like gliding than as an actual island flap.

EDB flap was first applied in 1973 by Barfred and Reumert ${ }^{8}$ to cover a wound of the lateral malleolus. It has been highlighted in microsurgical way for reconstruction as functional transplantation for chronic facial paralysis, ${ }^{9,10}$ after being replaced by the use of the pectoralis minor, serratus anterior and gracilis.

From its description, few reports have been published in the literature ${ }^{11-16}$ and only in 2003, Martinet et al., ${ }^{17}$ Chattar-Cora and Pederson ${ }^{18}$ and Chateau et al. ${ }^{19}$ published a significant number of cases, with respectively 15,20 and 52 patients operated on this technique and with good results. From 2009, we started our personal clinical experience with the flap.

The aim of the study was to evaluate retrospectively the results obtained in patients undergoing surgery in which we use EDB as skin muscle flap coverage and as tissue to fill cavities after surgical treatment of chronic osteomyelitis in the foot, ankle and distal leg, as well as to determine its clinical feasibility and analyze possible complications especially on the donor area.

We did not find in the national literature searched (SciELO and LILACS databases) any report of this technique.

\section{MATERIALS AND METHODS}

In the period between November 2009 and July 2012 eleven patients were operated with the EDB flap technique, nine men and two women, aged between 10 and 66 years old. Indications

All the authors declare that there is no potential conflict of interest referring to this article.

1. Institute of Orthopedics and Traumatology, Hospital das Clínicas, FMUSP, São Paulo, SP, Brazil.

Work performed at Laboratory of Investigation of the Musculoskeletal System (LIM 41), Department of Orthopedics and Traumatology, Faculdade de Medicina, Universidade de São Paulo Correspondence: Rua Ovídio Pires de Campos 333, 3o andar, Secretaria Médica, 05403-010, São Paulo, SP, Brasil. lucrut@terra.com.br 
included treatment of wound raw area related to acute trauma in four patients and post-traumatic osteomyelitis in seven patients. The defects were covered with small flaps ranging from $3 \times 3$ to $6 \times 3 \mathrm{~cm}^{2}$.

In two patients the flap was a reverse flow to cover the forefoot. (Figure 1) In nine patients the flap was anterograde. (Figure 2) Of the nine anterograde flaps, in five patients the flap was transposed to the medial region of the distal end of the leg. In four patients the flap was applied to the lateral face of the ankle. In one patient (patient \# 9) a random fasciocutaneous flap was associated concomitantly.

In both retrograde flaps (i.e., when ligature of the anterior tibial artery is done and the flow comes from the first dorsal metatarsal artery) flaps covered the first commissure and the dorsum of the foot, respectively.

Patients were evaluated according to the following criteria: viability of the flap, resolution of skin defect, healing of chronic infection, dehiscence of the donor area and the need for additional procedures. As subjective criteria, we assessed the satisfaction level of the patient on the procedure.

\section{RESULTS}

All patients operated with the technique included in the study had a minimum follow-up of 12 months, ranging from 1 to 4 years after surgery.

Ten of eleven flaps were viable. There were flaps with partial suffering. The unviable flap was completely lost. In all cases, except for the loss, there was complete healing of the skin defect and cure of chronic osteomyelitis with EDB flap during follow-up, with no recurrence episodes.

We had problems with dehiscence of the donor site in five of 11 patients ( $45 \%$ of patients with viable flaps). Of the five patients with dehiscence of the donor area, four progressed to complete healing only with outpatient dressings (superficial wounds). In a patient who presented with exposure of tendons and bones, it was necessary to use a reverse sural flap to cover the donor site on the dorsum of the foot.

For the patient who presentad total flap loss, a new flap was required (a reverse flow sural chimeric flap, with a portion of the lateral gastrocnemius muscle). After this procedure, there was skin coverage healing, cure of osteomyelitis and bone consolidation.

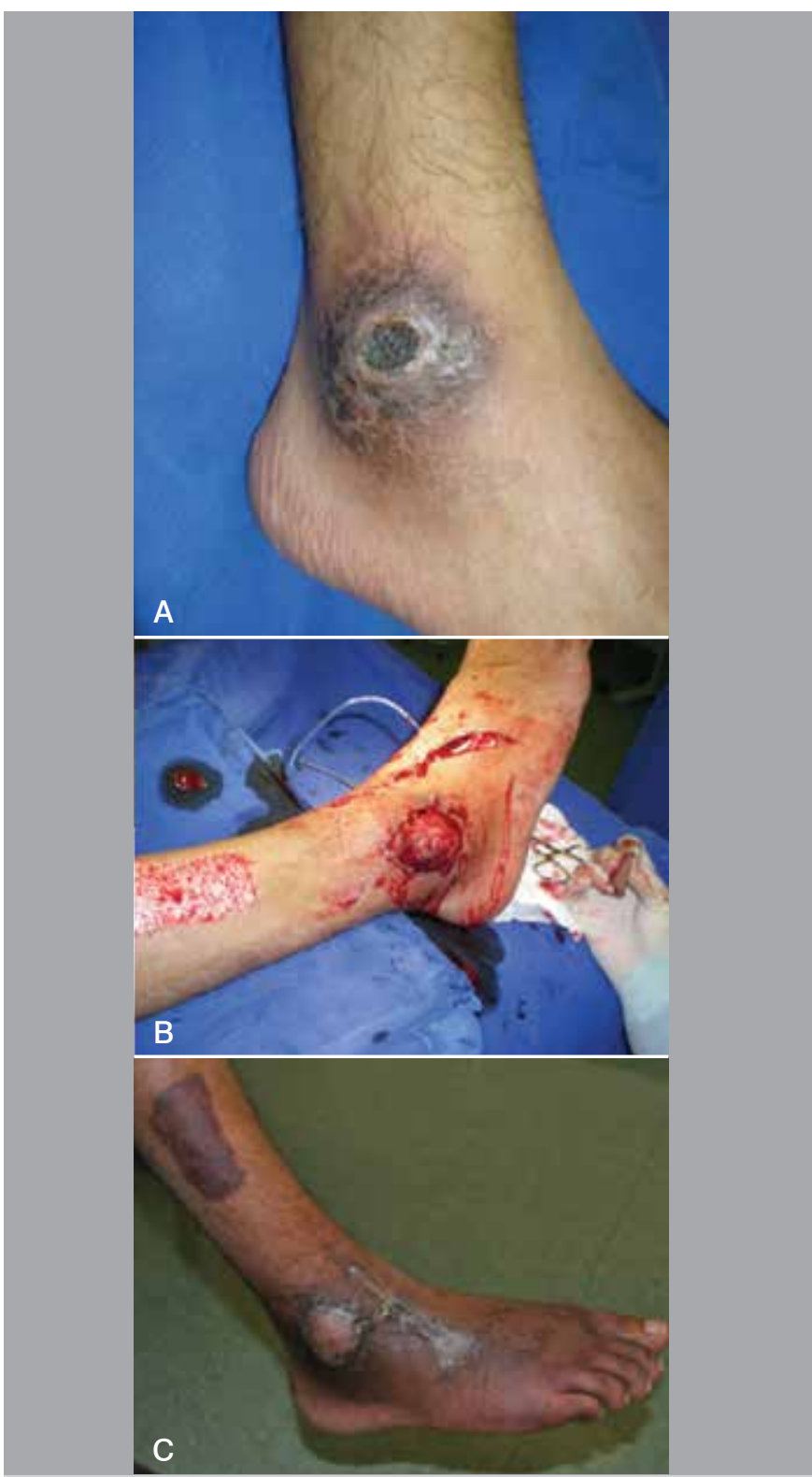

Figure 2. (Patient \#4) (A) Skin necrosis on the right lateral malleolus (B) Retail positioned via a subcutaneous tunnel and donor site in healing process (C) Retail and donor area well healed.
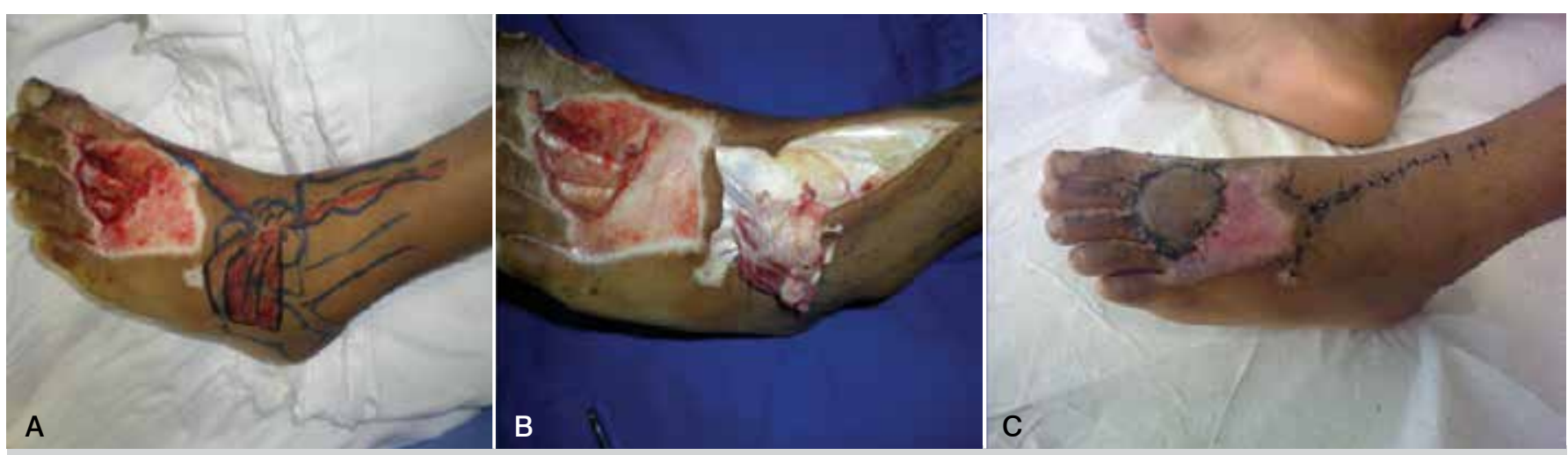

Figure 1. (Patient \#2) (A) Skin defect along the 1st and 2nd commissures with drawing of the graft planning, (B) Retail dissected with ligation of the anterior tibial vessel. (C) After skin grafting. 
We believe that EDB flap loss was likely caused by vascular damage related to prior dissection of the anterior compartment of the distal end of the leg by local bone graft.

All patients were satisfied with functional and aesthetic results. The patient that had complete loss of the flap was also satisfied, since he considered that there was minimal damage to the donor site.

The results are summarized in Table 1.

\section{DISCUSSION}

The elevation of the flap based on the anterior tibial artery $/ 1^{\text {st }}$ dorsal metatarsal allowed for perfect positioning of the muscle along the defects.

Like any muscle flap, dissection plans are quite clear and this facilitates their lifting. Also like any muscle flap it is necessary to remove a skin graft blade, sacrificing additional donor area. Our results corroborate data from the literature, ${ }^{17-19}$ which consider EDB pedicle flap in the anterior tibial artery or the first metatarsal dorsal artery feasible and safe.

In the case of loss (patient \#7), it was necessary to dissect the proximal pedicle of the flap in a region previously addressed by surgery, affected by fibrosis and adhesions. The authors consider that this should be avoided at all costs, switching the indication for surgery in these situations.

The rate of problems in the donor area of the muscle was very high. Although most of them (4/5 dehiscence) has been solved only with dressing changes, in the most time consuming of them (patient \#11), the complete healing of the donor site occurred at 12 weeks, which definitely delayed full rehabilitation of the patient. The dehiscence and delayed wound healing is probably related to vascular compromise of the flap surface integument of EDB (perforating cutaneous vessels). In the most dramatic case (patient \#9), it was necessary to use a reverse sural flap for treatment of donor site. This patient presented with extensive skin necrosis in the region. We associated the magnitude of cutaneous suffering in the donor area to the type of incision to lift the flap of the EDB. The rectilinear longitudinal accesses cause less cutaneous vascular suffering. Moreover, "L" shaped incisions or with some angle or vertex, associated with a higher skin suffering by causing major damage to vessels and the skin septal subdermal vascular system.

Although the rectilinear longitudinal incisions may hinder flap elevation, we considered prohibitive "L" shaped incisions on the donor area of the EDB muscle. (Figures 3 and 4) Likewise, we also disagree with Kim et al. ${ }^{20}$ that describes the use of two parallel incisions for flap elevation, as a solution for skin suffering observed in the donor area. We believe that the technique has been described in only three cases, all about the muscle with reverse flow. The examples in this paper do not represent the actual clinical practice found in the majority of cases in the literature. We consider the high risk of skin suffering in the range of parallel incisions due to the involvement of irrigation skin after removal of the muscle.

The authors continue performing EDB flap as a top choice for small defects of the foot and ankle, as well as cavitary osteomyelitis of the distal $1 / 3$ of the leg.

Table 1. Characteristics of results from eleven patients operated in this study.

\begin{tabular}{|c|c|c|c|c|c|c|c|}
\hline 1 & $\mathrm{~F}$ & 33 & osteomyelitis (post-traumatic) & Ankle lateral & $6 \times 3$ & Nov/24/2009 & Piod gangrenosum \\
\hline 2 & M & 10 & Trauma & $1^{a}$ commissure foot & $3 \times 3$ & Dec/29/2009 & None \\
\hline 4 & M & 24 & osteomyelitis (post-traumatic) & Ankle lateral & $3 \times 3$ & Mar/2/2010 & None \\
\hline 5 & M & 57 & osteomyelitis (post-traumatic) & $1 / 3$ dist leg & $3 \times 3$ & Aug/12/2010 & None \\
\hline 6 & $\mathrm{~F}$ & 42 & osteomyelitis (post-traumatic) & $1 / 3$ dist leg & $3 \times 3$ & Jan/12/2011 & Donor site dehiscence \\
\hline 8 & M & 66 & osteomyelitis (post-traumatic) & $1 / 3$ dist leg & $3 \times 3$ & Feb/1/2012 & Donor site dehiscence \\
\hline 9 & M & 39 & Exposition of synthesis mat. & Ankle lateral & $3 \times 3$ & $\mathrm{Jul} / 3 / 2012$ & Donor site dehiscence \\
\hline 10 & $M$ & 29 & osteomyelitis (post-traumatic) & $1 / 3$ dist leg & $3 \times 3$ & $\mathrm{Jul} / 13 / 2012$ & None \\
\hline 11 & M & 50 & trauma (compound fracture) & Dorsal forefoot & $3 \times 3$ & $\mathrm{Jul} / 25 / 2012$ & Donor site dehiscence \\
\hline
\end{tabular}




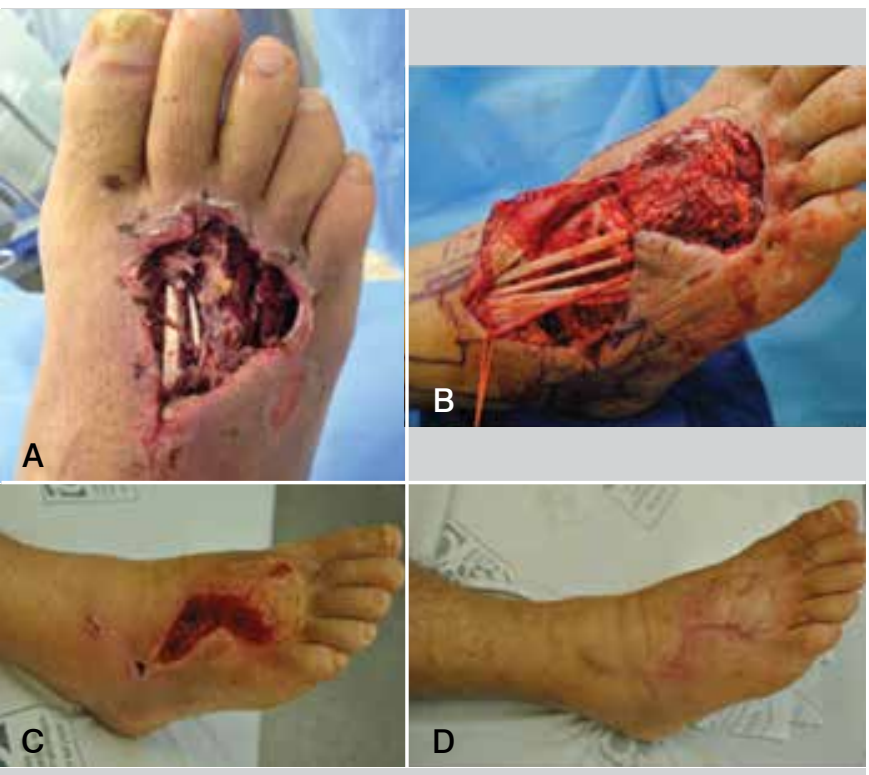

Figure 3. (Patient \#11) (A) Postoperative aspect of compound fracture of the metatarsals with bone-tendon exposure and plates after skin necrosis. (B) "L" shaped access, dissection of EDB flap and positioning over the wound. (C) Good integration of blade flap and graft, showing, however, dehiscence of borders in the donor area. (D) Complete wound healing after 12 weeks.

\section{CONCLUSÃO}

The EDB flap is feasible and safe for foot, ankle and distal leg losses. There is the possibility of suffering, dehiscence and delayed healing of the end flap donor area of EDB.
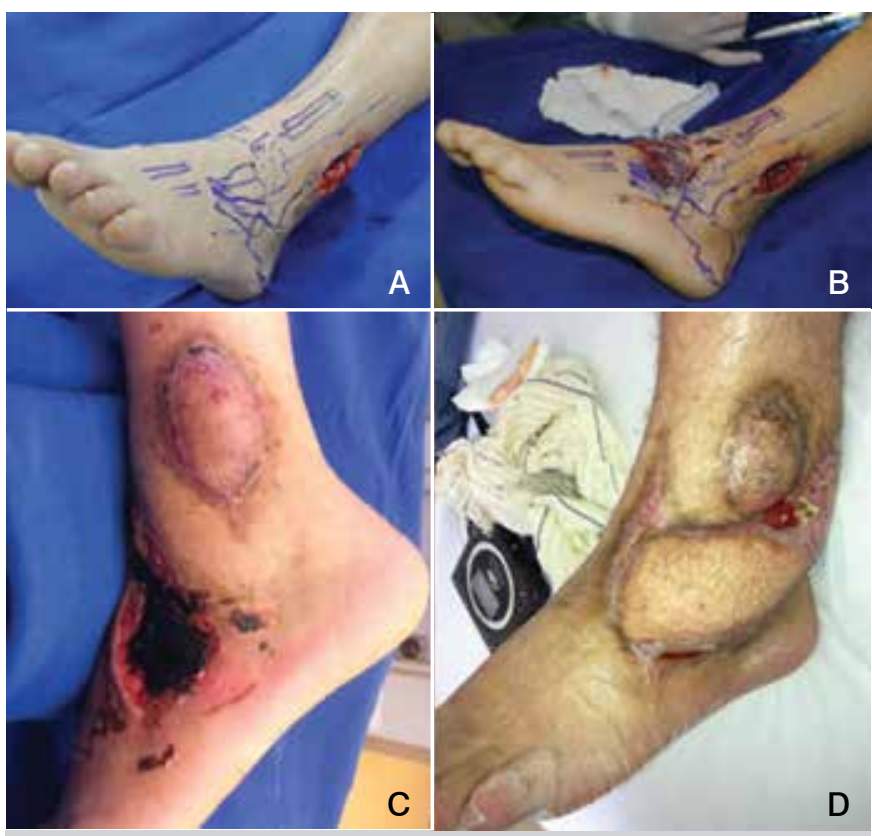

Figure 4. (Patient \#9) (A) Planning of the flap and defect with exposure of the plate in the lateral malleolus (B) Dissected graft, it is noted that the incision made an "L" (C) Necrosis of the skin overlying the muscle donor area (D) postoperative of sural flap healed.

Such complications can be minimized with incisions that preserve the cutaneous vasculature of the donor area (rectilinear longitudinal incisions).

\section{REFERENCES}

1. Koshima I, Soeda S. Inferior epigastric artery skin flaps without rectus abdominis muscle. Br J Plast Surg. 1989;42(6):645-8.

2. Angrigiani $C$, Grilli D, Siebert J. Latissimus dorsi musculocutaneous flap without muscle. Plast Reconstr Surg. 1995;96(7):1608-14.

3. Teo TC. Perforator local flaps in lower limb reconstruction. Cir Plas Iberolatinoam. 2006;32(4):287-92.

4. Al-Qattam MM. A modified technique for harvesting the reverse sural artery flap from the upper part of the leg: inclusion of a gastrocnemius muscle "cuff" around the sural pedicle. Ann Plast Surg. 2001;47(3):269-78.

5. Georgescu AIV. Microsurgical non-microvascular flaps in upper limb reconstruction. In: Proceedings of the III Congress of the World Society for Reconstructive Microsurgery - WSRM. Medimond: Buenos Aires; 2005. p. 9-14.

6. Badgley CE. Coalition of the calcaneus and navicular. Arch Surg. 1927;15(1):75-88.

7. Fuson S, Barrett M. Resectional arthroplasty treatment for calcaneonavicular coalition. J Foot Ankle Surg. 1998;37(1):11-5.

8. Barfred T, Reumert T. Myoplasty for covering exposed bone or joint on the lower leg. Acta Orthop Scand. 1973;44:532-8.

9. O’Brien BM. Microvascular reconstructive surgery. Churchill Livingstone: New York; 1977.

10. O'Brien BM, Franklin JD, and Morrison WA. Cross-facial nerve grafts and microneurovascular free muscle transfer for long established facial palsy. $\mathrm{Br} \mathrm{J}$ Plast Surg. 1980;33:202-15.

11. Landi A, Soragni O, Monteleone M. The extensor digitorum brevis mus-

cle island flap for soft-tissue loss around the ankle. Plast Reconstr Surg. 1985;75(6):892-7.

12. Leitner DW, Gordon L, Buncke HJ. The extensor digitorum brevis as a muscle island flap. Plast Reconstr Surg. 1985;76(5):777-80.

13. Ismail TI. The dorsalis pedis myofascial flap. Plast Reconstr Surg. 1990;86(3):573-6.

14. Buncke HJ. Microsurgery: Transplantation--Replantation: An Atlas-text. Philadelphia: Lea \& Febiger; 1991.

15. Mandrekas AD, Zambacos GJ, Grivas TM. The extensor digitorum brevis muscle flap for the reconstruction of soft tissue defects in the lower limb. Eur J Plast Surg. 1995;18(2-3):82-4.

16. Bakhach J, Demiri E, Chahidi N, Baudet J. Extensor Digitorum Brevis muscle flap: new refinements. Plast Reconstr Surg. 1998;102(1):103-10.

17. Martinet X, Forli A, Guinard D, Corcella D, Moutet F. Extensor digitorum muscle flap: its position in ankle and foot coverage. Report of 15 cases. Ann Chir Plast Esthet. 2003:48(3):159-66.

18. Chattar-Cora D, Pederson WC. Experience with the extensor digitorum brevis muscle flap for foot and ankle reconstruction. Ann Plast Surg. 2006;57(3):289-94.

19. Chateau F, Chabas JF, Niddam J, Guinard D, Legré R. Use of extensor digitorum brevis flap in routine reconstructive surgery of lower limbs. Report of more than 50 cases. Ann Chir Plast Esthet. 2012:57(6):600-5.

20. Kim JK, Choi SJ, Chung MS, Baek GH. Extensor digitorum brevis muscle flap using parallel incision. J Plast Reconstr Aesth Surg. 2009;62(10):1317-20. 